\section{Commentary: Equivalence is not enough}

\author{
Craig R. Smith, MD
}

Taggart and colleagues ${ }^{1}$ have done an exhaustive comparison of on-pump versus off-pump (OPCAB) coronary artery bypass grafting in the Arterial Revascularization Trial. The authors are not pretending that a post hoc subgroup analysis is a randomized trial. Even so, this exercise retains some of the benefits of a randomized trial, such as strict entry criteria, exacting data definitions, rigor of ascertainment, and completeness of follow-up. A good case is made for equivalence of the 2 approaches with respect to death, myocardial infarction, stroke, and repeat revascularization, with admirable 10-year follow-up. Very importantly, lowvolume OPCAB surgeons had significantly worse results. Therefore, equivalence was achieved on the strengths of the most highly skilled and experienced surgeons who enrolled patients in the trial.

Readers old enough to remember the origins of the OP$\mathrm{CAB}$ movement will recall that it was driven by a desire to offer something "less invasive" to compete with percutaneous coronary intervention. OPCAB seemed especially attractive because it avoided the heart-lung machine. At the time, the Internet overflowed with lurid tales of socalled pump head that added 20 minutes to each preoperative consult discussion of heart surgery. As time went on, well-conducted clinical trials overwhelming failed to show reductions in cognitive dysfunction or stroke with use of OPCAB, and the great majority of the trials found that OPCAB was associated with more graft failures and fewer distal anastomoses. This reached something of a watershed in $2014,{ }^{2-4}$ at which point this previously devoted OPCAB surgeon switched back to on-pump as his default for coronary artery bypass grafting.

With that history in mind, readers should wonder how this level of equivalence helps OPCAB. OPCAB is hard to learn and harder to master. It has failed to provide any

From the Department of Surgery, Vagelos College of Physicians \& Surgeons of Columbia University, and Columbia University Irving Medical Center of New York Presbyterian Hospital, New York, NY.

Disclosure: Author has nothing to disclose with regard to commercial support.

Received for publication March 5, 2020; accepted for publication March 5, 2020; available ahead of print March 18, 2020.

Address for reprints: Craig R. Smith, MD, Columbia University Irving Medical Center of New York Presbyterian Hospital, 177 Fort Washington Ave, Milstein Building 7-435, New York, NY 10032 (E-mail: crs2@cumc.columbia.edu).

J Thorac Cardiovasc Surg 2021;162:600-1

$0022-5223 / \$ 36.00$

Copyright (c) 2020 by The American Association for Thoracic Surgery

http://dx.doi.org/10.1016/j.jtcvs.2020.03.023

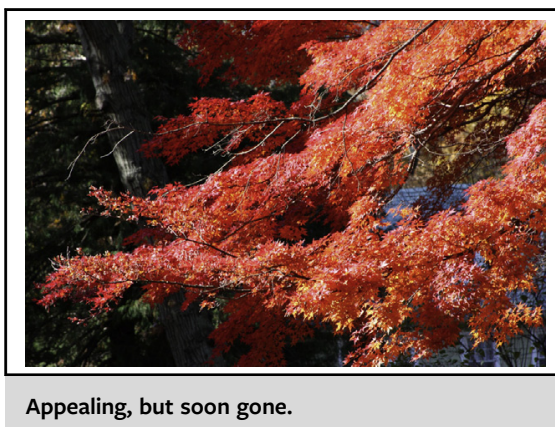

CENTRAL MESSAGE

Equivalence always favors the

simpler of 2 options, in this case

favoring on-pump coronary

bypass over off-pump. To revive

off-pump requires superiority for

important objective outcomes.

of the major advantages that made mastery appear worth achieving. Equivalence shows that simpler alternatives are just as good. The authors describe "some advantage" for $\mathrm{OPCAB}$ with respect to transfusion and postoperative atrial fibrillation. Those outcomes do not remotely compare in importance to stroke, cognitive dysfunction, completeness of revascularization, and graft patency, and the differences are not large; the advantage for OPCAB is $10.1 \%$ versus $13.2 \%(P=.04)$ for transfusion, and $22.9 \%$ versus $27.4 \%$ for atrial fibrillation $(P=.02)$.

The authors speculate that OPCAB results were compromised by underutilization of a bilateral internal thoracic artery (BITA) grafting strategy. They are well known advocates of that strategy in general, on or off pump. BITA happens to match my personal bias, and has reasonable support in the literature. Considerable statistical firepower was applied to this hypothesis, concluding only that "BITA versus [single internal thoracic artery] grafting was not an effect modifier in the comparison between offpump versus on-pump surgery."

An unpowered Arterial Revascularization Trial subgroup that was not prespecified does not disprove that OPCAB could be superior with greater reliance on BITA. But is that hypothesis worth pursuing? Even if a randomized comparison of multiarterial OPCAB to on-pump could be carried out by the shrinking handful of surgeons left in the world who have enough operative volume to claim genuine expertise in both approaches, what influence would a positive result have? Widespread adoption of OPCAB by all 
coronary surgeons has already failed once, and would fail again.

\section{References}

1. Taggart DP, Gaudino MF, Gerry S, Gray A, Lees B, Sajja LR, et al. Ten-year outcomes after off-pump versus on-pump coronary artery bypass grafting: insights from the Arterial Revascularization Trial. J Thorac Cardiovasc Surg. 2021;162:591-9.e8.
2. Houlind K, Fenger-Grøn M, Holme SJ, Kjeldsen BJ, Madsen SN, Rasmussen BS, et al. Graft patency after off-pump coronary artery bypass surgery is inferior even with identical heparinization protocols. Results from the Danish on-pump versus off-pump randomization study (DOORS). J Thorac Cardiovasc Surg. 2014;148: 1812-9.

3. Kim JB, Yun SC, Lim JW, Hwang SK, Jung SH, Song H, et al. Long-term survival following coronary artery bypass grafting. J Am Coll Cardiol. 2014;63:2280-8.

4. Smith CR. \#SLOPCAB: is the party over? J Thorac Cardiovasc Surg. 2014;148: 1788-9.
See Article page 591.

\section{Commentary: Coronary surgery AR'T and two tablets for a headache}

\author{
Chaim Locker, MD
}

The ART (Arterial Revascularization Trial) ${ }^{1}$ investigators submit another post-hoc study with important insights from the trial. They investigated one of the more controversial subjects in coronary surgery: outcomes of off-pump versus on-pump coronary artery bypass grafting (CABG). They compared 1252 patients who underwent off-pump CABG with 1699 on-pump CABG patients enrolled in the ART. ${ }^{2}$ Ninety-five percent of patients completed 10 years of follow-up. The authors used propensity matching (1078 pairs of patients) and mixed-effect Cox model to compare long-term outcomes between the 2 groups. They concluded that in the ART, off-pump CABG patients had similar risk of death over 10 years and similar risk of the composite of death, myocardial infarction, stroke, and repeat revascularization compared with on-pump CABG patients. Moreover, they claim that the equipoise between off-pump versus on-pump surgery was not influenced by the use of bilateral internal thoracic artery (BITA) and multiple arterial grafting versus single internal thoracic artery (SITA).

The authors should be commended for this investigation for several reasons. The quality and quantity of the data are undoubtedly excellent. The authors are world-renowned

\footnotetext{
From the Department of Cardiovascular Surgery, Mayo Clinic, Rochester, Minn Disclosures: Author has nothing to disclose with regard to commercial support. Received for publication March 1, 2020; accepted for publication March 3, 2020; available ahead of print March 19, 2020.

Address for reprints: Chaim Locker, MD, Department of Cardiovascular Surgery, Mayo Clinic, 200 First St SW, Rochester, MN 55905 (E-mail: lekerlocker. chaim@mayo.edu).

J Thorac Cardiovasc Surg 2021;162:601-3

$0022-5223 / \$ 36.00$

Copyright (c) 2020 by The American Association for Thoracic Surgery

http://dx.doi.org/10.1016/j.jtcvs.2020.03.021
}

Check for updates

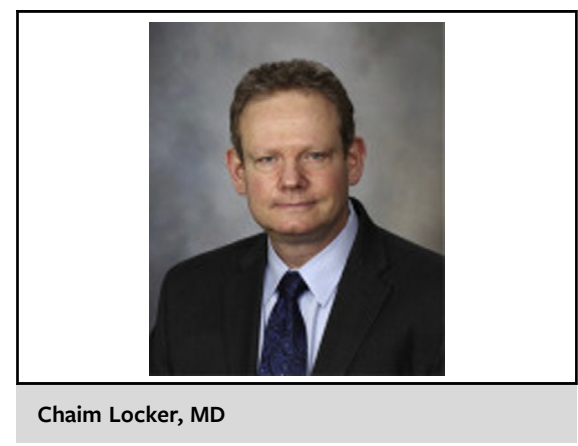

CENTRAL MESSAGE

In the ART off-pump and on-

pump CABG are associated with

similar long-term outcomes. The

insights from the ART are very

important and reflect the need

to define coronary surgery as a

subspecialty.

experts in coronary surgery, and the quality of analysis and the construction of the manuscript are outstanding. Moreover, their courageous investigation and thoughtful analysis may indicate on some additional flaws in the construction and preset of the ART, but alternatively, could be considered as important contributing insights to "real-life practice."

However, there are some questions and comments to be raised:

1. The authors present superb results of the off-pump group with: (1) comparable number of grafts $>3$ in the offpump versus on-pump group. (2) Only $2.5 \%$ conversion rate from off-pump to on-pump surgery. (3) Rates of 3-vessel-disease and "worse quality of native vessels" were more prevalent in the off-pump group. (4) BITA grafts were more likely to be used in the off-pump group, which is unexpected for itself, and as previously shown 